Rev. Asoc. Esp. NeuropsiQ. 2020; 40(I 37): 205-208

DOI: I0.432I/So2 I I-57352020000 I000IO

\title{
La clínica del sujeto
}

The clinic of the subject

Piedad Ruiz Castillo

Psicóloga clinica. Psicoanalista. Madrid.

Correspondencia: piedadruiz7@gmail.com

Francisco PEREÑA (2019), Cómo pensar la clínica del sujeto, Madrid, Editorial Síntesis. ISBN: 978-84-9171-442-2, 253 páginas.

C Ste libro contiene diez clases impartidas por F. Pereña y trasladadas a la Eescritura de una manera sensible y profunda, si entendemos por "profundo" el sentimiento de la vida humana en su profunda alteración y desconcierto. En ellas transmite, quizás de una forma conclusiva, su enseñanza publicada en doce libros desde 2001 a 2019. A lo largo de su obra, el autor ha construido una manera propia de pensar, en la que, por no evitar la complejidad, empuja al debate y hace de la clínica su campo de batalla. De ahí que en su nota introductoria hable de su "oficio" como una práctica que "se da a pensar" y que, en este caso, se da a pensar como una clínica del sujeto cuyos fundamentos se prefiguran en un extenso índice que el lector agradecerá por ser muy orientativo sobre su contenido. A su vez, el lector encontrará en el texto múltiples referencias de otros autores que le han acompañado a lo largo de su transmisión oral y escrita, unas veces para reconocer su valor y otras para realizar una tarea crítica. Ahora bien, es la referencia freudiana la que está constantemente presente, sus valiosas contradicciones y los hallazgos que inspiran sus aportaciones.

El principal hallazgo freudiano, al que el autor vuelve una y otra vez, es la concepción de la pulsión, que encontramos ya en el Proyecto de una psicología para neurólogos, ligada a la idea de alteridad y que Pereńa define como "alteración pulsional" por la presencia que tiene el otro en "el propio existir del sujeto". No menos 
inspiradoras son otras ideas freudianas como los desarrollos sobre la "transformación de la angustia en afecto" o cómo Freud habla de separar la agresividad de la sexualidad como objetivo del tratamiento analítico, siendo el amor esa posibilidad casi utópica de "no hacer daño o, al menos, de no dañar lo que se ama". Pero también es necesario subrayar algunos de los errores freudianos que seńala el autor y que considera han tenido graves consecuencias para la clínica psicoanalítica: el dualismo pulsional que "biologiza" la pulsión y que llevó a muchos autores postfreudianos a abandonar dicho concepto. Probablemente, la aportación de F. Pereña consista en haber extraído de las contradicciones en las que se debate Freud el valor clínico de la pulsión señalado anteriormente. Sin embargo, su crítica a la teoría falocéntrica de la sexualidad es contundente, el "culto fálico" y el intento de legislar la sexualidad no son producto de ninguna contradicción, sino el reflejo del orden social de su época y de un sistema patriarcal, un orden social que "exalta a la mujer sagrada, a la vez que se excluye a la mujer deseante".

Uno de los ejes más interesantes que atraviesa el libro y que sostiene su clínica del sujeto es el concepto de elaboración. Si convenimos en que la escucha es la clave de la clínica psicoanalítica, su condición fundamental es la elaboración y no el par interpretación/resistencia, entendiendo por elaboración "un pensar que requiere al otro en un encuentro creativo". Para ello, es necesario que el clínico no intente ejercer el poder, no confunda desde "lo científico" la razón con la verdad y, sobre todo, no sustituya al sujeto por la doctrina. Para Pereńa, la experiencia inaugural de todo humano, que podemos pensar con la terminología freudiana como "angustia fundamental", se repite en cada encuentro, pero en el encuentro terapéutico no es solo el otro el que calma la angustia con su acogida, sino que es el propio sujeto el que elabora. El sujeto no es pasivo como se piensa desde un punto de vista madurativo, sino "activo y sentiente", siendo entonces la transferencia ese encuentro creativo, más congruente con la idea freudiana de "inconsciente dinámico". De esta manera, "la radicalidad del descubrimiento freudiano es lo que liga pulsión y sujeto, pulsión e inconsciente, frente a la deriva junguiana del inconsciente colectivo y frente a la pulsión anónima de Schopenhauer". La segunda teoría freudiana de la angustia como "causa" y no "efecto" de la represión supone para el autor el comienzo de una clínica del sujeto, pero de un sujeto concreto del dolor y del deseo, no como sujeto de la representación, no como efecto de una estructura, sino como "factum pulsional que hace de la angustia su condición misma de sujeto". De ahí que lo que haga cada sujeto con la angustia determinará su condición sintomática. Y, por otro lado, al definir el autor el inconsciente como la "huella de la experiencia del otro", esa "determinación sintomática" estará atravesada por el modo de sentir al otro y buscar acogida en su enigmático deseo, denominando "articulación de la demanda inconsciente" a esta constante e ineludible tarea del empuje a la vida. 
El segundo eje vertebrador del libro está dedicado a la psicopatología, destacando en este apartado su crítica al concepto de psicogénesis y al concepto de "estructura clínica". Es indudable que el sujeto como "acontecer vital" está determinado por cierta expresión genética y por el tipo de sociedad en que le toque vivir, aunque estos dos factores no operen como causa general y universal, y dejando claro que el criterio de normalidad no cabe en una clínica del sujeto. ¿Se puede hablar de una etiología de la pulsión?, se pregunta F. Pereña, a la vez que critica la determinación estructural que concibe al sujeto como efecto de una estructura frente a la determinación sintomática del sujeto que aparece en la clínica como "acontecer enigmático e impredecible". En la misma lógica, el autor cuestiona cualquier intento de establecer una etiología basada en "causa y efecto", subrayando por el contrario la posibilidad de establecer "criterios" diagnósticos orientativos y planteando una distinción esclarecedora entre fenómeno clínico (no como confirmación de un saber, sino como interrogante), sindrome (características o criterios que permitan cierta inteligibilidad) y sintoma (modo de sentir la angustia, el deseo y sus defensas).

En el terreno de los diagnósticos que muestran en nuestra época una prevalencia con sus consiguientes efectos en el mercado farmacológico y burocrático, Pereña se ocupa de algunos de ellos, como la depresión, el TDA-H o los trastornos del límite (como el autor denomina a los trastornos límites de la personalidad (1)). Plantea la depresión como fenómeno clínico y posible afectación de un sujeto, y no como un "cuadro autónomo fuera de la melancolía", a la vez que se pregunta si puede ser la respuesta del sujeto a una época de "consumo totalitario y sin sentido". En la clínica infantil, el TDA-H muestra igualmente algo de esta época, que carece de un tiempo para la experiencia que posibilite la creación de un mundo interno y de una demanda en el vínculo con los demás. En cuanto a los trastornos del límite, es frecuente que la dificultad terapéutica opere como criterio diagnóstico en estos casos, cuando esta dificultad puede presentarse en general cuando existe una "escasa capacidad de recibir del otro algo en lo que no predomine el daño y la frustración".

El recorrido por la psicopatología se centra en la distinción más clásica y operativa entre neurosis y psicosis, con una mención especial al autismo y al testimonio de Birger Sellin. Tomando la alteración pulsional o vacio pulsional como punto de partida de su pensamiento clínico, muestra por ejemplo cómo el psicótico nos enseńa este vacío como "abismo melancólico" o la necesidad de pertenencia en el delirio paranoico, mientras que el sujeto autista nos muestra una "soledad radical" en la búsqueda incesante de una "conexión con el mundo". El neurótico, sin embargo, construye un yo como espacio de relación con los demás, aunque el yo no es equivalente al sujeto, pues un yo sin sujeto siempre estará expuesto a la angustia, el exceso pulsional y la impulsividad, y un sujeto sin yo es un sujeto sin intimidad, sin unidad yoica, expuesto entonces a continuos pasos al acto. También, y a propósito 
de la neurosis, son interesantes las reflexiones del autor sobre el sujeto, el deseo y sus defensas, pues afirma que no hay deseo sin defensas, aunque estas pueden jugar a favor o en contra del propio deseo. Y como ejemplo sirva la diferencia entre la denegación y la disociación, pues la primera es integradora y componente fundamental en la formación del yo, mientras que la segunda muestra "su extremada cercanía a la angustia”. Y en este punto, Pereña se detiene para analizar la anorexia como rechazo disociativo en la percepción del cuerpo, cuerpo que ha sido libidinizado en el rechazo, subrayando la importancia de tratar en estos casos los vínculos libidinales más allá de este rechazo y entendiendo que los "ideales de pureza", como toda idealización, protegen del deseo, pero matan la vida. La neurosis, siempre cercada por la angustia de abandono y debatiéndose en el conflicto de defenderse del deseo y hacerlo posible, revela la "dificultad del sujeto obsesivo con la pérdida y la mayor cercanía del sujeto histérico con la angustia".

Por último, Pereńa plantea lo que considera "la extraordinaria intuición" de Freud al definir la sexualidad como traumática, intuición que, sin embargo, quedó sepultada en su empeño por legislarla. Intento inútil, porque si es traumática es precisamente porque no es posible encerrarla en ninguna identidad, al no ser ni natural ni meramente cultural y menos aún instintiva, como si hubiera "un modo de deseo y de satisfacción sexual normalizado". Y, como ocurre en la construcción de la subjetividad, donde no es suficiente la explicación genética o la cultural sin la determinación sintomática, en este caso igualmente no puede definirse a un hombre o a una mujer sin esa "perspectiva" sintomática. En cuanto al "monoteísmo peneano" freudiano o su versión fálico-lacaniana, con la que se ha legislado durante demasiado tiempo la diferencia sexual y el concepto nuclear del complejo de Edipo, Pereña no hace concesión alguna al afirmar lo siguiente: "En lo que a la clínica del sujeto se refiere, no me parece que sea posible sin cuestionar el «falicismo», para poder prestar atención al sujeto de la angustia y del dolor". Y como consideración general sobre la clínica del sujeto nos propone el reto de no ignorar aquello que el "grupo social ignora para constituirse como tal, es decir, la angustia, el miedo, la desesperación y el desamparo".

\section{BibLiografía}

(1) Pereña F. Denegación y límite. Acerca de los llamados trastornos límites. Rev. Asoc. Esp. Neuropsiq. 2009; 29(103): 7-33. 